\title{
Impresiones sobre Mayo Frances de 1968
}

\author{
Alejandro Simonoff ${ }^{1}$
}

Cuando Norberto Consani nos invitó a participar del ciclo de reflexiones, para aportar nuestras impresiones sobre la rebelión parisina de mayo de los sesenta, nos resultó estimulante. Si bien, inicialmente pensamos realizar una contribución más formal, luego nos pareció más adecuado presentar algo más ensayístico para abordarla de un modo más general.

Interrogarnos sobre sus cuestiones más estructurales, como las transformaciones de la economía mundial de posguerra, y otras, como los movimientos políticos que tuvieron lugar durante esa década, y que tuvieron en el París de 1968 uno de sus exponentes máximos, delinearon nuestra hoja de ruta.

Por otro lado, y más allá de las simpatías que nos generan las ideas que cobijaron ese movimiento antiburocrático y progresista, no nos impidieron observar sus secuelas en la actualidad.

\section{La economía y sociedad de posguerra}

La estructura socioeconómica de la última posguerra tuvo, hasta la crisis de 1973, como rasgo predominante la existencia de nuevos contratos sociales que impulsaron la llamada Edad Dorada. (Hobsbawn, 1996)

La universalización del Estado de Bienestar en los países más desarrollados (EE.UU., Europa Occidental y Japón) confirmaron aquella suscripción tendiente a revertir los problemas que ocasionó la Segunda Guerra Mundial e instrumentar un sistema de distribución de la riqueza que evite la llegada de una nueva conflagración mundial. Este rol reasignando recursos de manera más equitativa, no sólo buscaba evitar el surgimiento de nuevos Hitler en los países desbastados por la contienda, sino también para que no caigan en el comunismo.

Por su parte, los países socialistas constituyeron economías centralizadas y planificadas, todas girando en torno a las necesidades de Moscú y en los cuales se produjo una mejora de los niveles de vida, pero constituyendo sociedades estrechamente vigiladas.

En el caso de los países subdesarrollados, muchos de ellos optaron por estrategias desarrollistas consistentes en que los Estados busquen recursos en el exterior para financiar su industrialización, otros profundizaron su rol de exportador de materias primas, y un último grupo que tomó al modelo soviético como norte.

\footnotetext{
${ }^{1}$ Profesor del Doctorado y la Maestría en Relaciones Internacionales, IRI-UNLP
} 
Todas esas estrategias, repercutieron en un crecimiento acelerado de la economía mundial durante las dos primeras décadas de la posguerra, pero este proceso comenzó a mostrar signos de agotamiento en los años sesenta, cuando esa expansión se volvió más lenta. En los países desarrollados, se observó una decadencia industrial, sobre todo en el rubro siderúrgico, que comenzaron a ser desplazadas por la generación de empleo por parte del tercer sector (servicios) y relocalizándose hacia zonas de menores salarios que produjo, no sólo una fuga hacia el Lejano Oriente, sino que también comenzó un lento remplazo del modelo fordista por otro más reticular y flexible. (los NICS del sudeste asiático, p.e. $)^{2}$

Desde el punto de vista de la agricultura, las políticas proteccionistas del Primer Mundo, ya sea por medidas paraarancelarias, o por la implementación de subsidios directos e indirectos, comenzaron a distorsionar el rol de la periferia como proveedor de alimentos y materias primas afectando a los empleos rurales y fortaleciendo la conurbación urbana en sus grandes ciudades.

Estas transformaciones impactaron sobre el comportamiento de la clase obrera. La mejora del nivel de vida, producto del pleno empleo y el consumo de masas, llevó a ciertos cambios, tenues en esos momentos donde los trabajadores cualificados comenzaron a votar a la derecha, o a la extrema derecha y no por sus opciones progresistas tradicionales (socialdemócratas o comunistas). Ello fue observado con distintos matices por Castoriadis (2009) quien sostuvo el aburguesamiento de los obreros industriales, o por Hobsbawm (1995) quien hizo hincapié en una división funcional entre los de cuello blanco (white collar), vinculados a los servicios y que viraron hacia los conservadores, y los de cuello azul (blue collar, o de overol) quienes también cambiaban sus lealtades políticas.

Dentro esta gran transformación social y política de las primeras décadas de la posguerra, uno de los aspectos más relevantes, fue la inversión estatal en educación. Se vio reflejado en el aumento del acceso a todos sus niveles, incluido el universitario, cuyas aulas se vieron desbordadas por los nuevos alumnos, provenientes mayoritariamente de los sectores medios, y en menor medida de los bajos, que reclamaban otro tipo de relaciones, más democráticas, en instituciones marcadas por la jerarquía y sumamente estratificadas

Aunque, como señala acertadamente Tony Judt (2009), el crecimiento de la matrícula universitaria que no tenía precedente, esta no alcanzaba a englobar a todos los jóvenes, ni permitió constituir una clase social, pero sí visualizar a un nuevo tipo de actor muy activo.

La aparición de los jóvenes como un actor diferenciado, no se desarrolló sólo política, sino también económicamente, como un nicho de consumo particularizado, por sus hábitos de vestimenta, de alimentación e insumos culturales.

En los Estados Unidos, como en la mayoría de las sociedades involucradas en la Segunda Guerra Mundial, aconteció el baby boom que no fue solo cuantitativo, sino también cualitativo, ya que se hicieron evidente las diferencias generacionales que permitieron reforzar el desarrollo de un mundo juvenil. Este fue estimulado por la cinematografía (recordemos por un momento a la figura de James Dean) que ensalzaba su rebeldía y potenciada por el surgimiento del rock and roll. Aunque su aparición en el mundo anglo-

\footnotetext{
${ }^{2}$ Los NICS (siglas en inglés de nuevos países industriales) fue claramente distinto al desarrollista, ya que se apoyó en el uso de mano de obra intensiva barata por parte del capital concentrado y no por reproducir la lógica de contrato social y estimulo estatal para industrialización.
} 
sajón, más tarde global, parecía más permeable al mercado que la política a la inversa que en Europa continental, pero esos caminos se mostraron más sinuosos.

\section{Los años sesenta}

Esa década puede ser conceptualizada, saliendo de los estrictos márgenes cronológicos, como lo hizo Jamenson (1997), a partir de las luchas del Tercer Mundo contra las potencias imperialistas, como Francia o Estados Unidos, bajo la imagen de David contra Goliat, que estimularon las protestas en esos países, los cuales fueron los mayores epicentros de esas movidas, y por ello la ubicó entre la Revolución Cubana en 1959 y la caída de Salvador Allende en Chile y la Crisis global de 1973.

Los ciclos de tensión, no fueron novedosos, los podemos rastrear con alguna certeza desde los tiempos de la doble revolución política y económica iniciada a fines del Siglo XVIII, como observamos en 1789, 1848 y 1917 por ejemplo.

En Estados Unidos, la mejora de la calidad de vida y las luchas por derechos civiles siguieron las mejores tradiciones del New Deal por parte de los gobiernos demócratas de Kennedy y Johnson con su programa de Great Society. Pero, por otro lado, esas administraciones se fueron involucrando cada vez más en el conflicto vietnamita, dado el rol hegemónico de Washington como cabeza del bloque occidental -y donde reemplazaron a los franceses en ese rol tutelar en la antigua Indochina- con el envío de "asesores" que cumplieron funciones militares contra el Frente de Liberación Nacional de Vietnam.

Esta intervención fue ganando la luz pública primero con el apoyo al régimen de Diem en 1961 y tres años después con la declaración formal de guerra. A diferencia de ocasiones anteriores, esta participación en la guerra del sudeste asiático no pudo ser legitimada, ya que fue rechazada por amplios sectores de la sociedad civil norteamericana, y expresada a través del pacifismo.

Pero esas protestas no se detuvieron en el gran país del norte y se extendieron a sus socios europeos, cuyas principales capitales fueron testigos de esas marchas también multitudinarias, que muy bien las reflejaron por los Rolling Stones cuando en "Luchador Callejero", expresaban: "Por doquier escucho el sonido de pies cargando y marchando, chico / Porque el verano está aquí y es el momento correcto para pelear en la calle, chico/ Pero qué puede hacer un pobre muchacho / Excepto cantar en una banda de rock and roll..." (Jagger y Richards, 1968) ${ }^{3}$

El bloque Oriental no escapó a estas tensiones, como se pudo observar en el estaIlido de la Revolución Cultural en 1966. Desde los inicios de la República Popular China, en 1949, existieron pujas entre la burocracia partidaria y el liderazgo de Mao, se sumó a esto la promoción de una vía propia de llegada al socialismo. Las masas jugaron un papel crucial en el reclamo de una mayor descentralización económica y fortalecimiento de la figura del Gran Timonel, con su "Libro Rojo" como bandera.

\section{Y en eso llegó el Mayo francés}

\footnotetext{
${ }^{3}$ Nótese aquí la tensión entre cierta simpatía por los reclamos, pero a su vez su desconfianza con esas políticas.
} 
Los ingresos masivos a las universidades, producto de la inversión realizada en la Era Dorada, hicieron crujir una institución fuertemente estamental y la negativa a democratizar sus estructuras, en ese sentido la incomodidad de Raymond Aron (1982), con la nueva situación nos resultó muy significativa.

Los reclamos estudiantiles por los problemas habitacionales en la Universidad de Nanterre a principios de 1968 generaron la aparición pública de Daniel Cohn-Bendit, conocido como Dany el Rojo.

El 22 de marzo, se produjo la primera toma de la Universidad de Nanterre por las regulaciones en el uso de las instalaciones que llevaron a la intervención de la $\operatorname{CRS}^{4}$ y el encarcelamiento de algunos de sus dirigentes.

Los reclamos por transformar las situaciones cotidianas pronto mutaron a la forma de gobierno universitario, donde exigieron la participación de los estudiantes, pero la negativa de las autoridades llevó a un estado de efervescencia cada vez mayor. ${ }^{5}$

Un mes después, en una nueva protesta, motivada por las prohibiciones de las autoridades a realizar expresiones contra la guerra de Vietnam, éstas decretaron el cierre de la universidad para impedirla, a lo cual, los estudiantes respondieron llamando a un boicot para los exámenes parciales, que fue desautorizado por la Federación Nacional de Estudiantes de Francia -conducido por sectores de derecha- que concluyeron con enfrentamientos entre ambas facciones del estudiantado.

El movimiento fue ampliando su circunscripta agenda universitaria a muchos aspectos que cubrían un amplio espectro de reclamos sociales y políticos en los que se evidenciaba .su carácter anti-burocrático.

La ebullición fue en ascenso desde los primeros días de mayo cuando el movimiento traspasó los límites de la Universidad con ocupaciones de espacios públicos, primero a la Plaza de la Sorbona, y luego todo el Barrio Latino en donde la represión lejos de hacer retroceder a los manifestantes los envalentonaba.

Barricadas, marchas y grafitis dieron a este movimiento un carácter singular, la mayoría de las obras recuerda las escrituras callejeras como "sean realistas, pidan lo imposible" o "no tomen el ascensor, tomen el poder" consignas de una extensa lista que mostraron su estilo claramente irreverente. ${ }^{6}$

Fue la llamada "Semana Rabiosa" cuando comenzaron a sumarse comisiones obreras que estructuraron un sistema de control de precios y distribución de mercaderías. Esta obligó a la estructura sindical, en manos de los comunistas, a cambiar su mirada sobre esta revuelta de "nenes de papá" como la habían llamado en sus primeros días, y tratar de reconducir el proceso. Por ello, el día 13, la CGT se sumó y lanzó una huelga general por la que Francia resultó paralizada.

\footnotetext{
4 Son las siglas en francés de la Compagnies Républicaines de Sécurité (Compañías Republicanas de Seguridad) que son fuerzas de seguridad de la Policía Nacional francesa.

5 Este reclamo resulta curioso, ya que la participación estudiantil en el cogobierno de la universidad era algo que en estas costas se había logrado, no sin rupturas, unos cincuenta años antes con la Reforma Universitaria-,

6 Aunque para ser sinceros, muchas de esas pintadas resultaban contradictorias entre sí: algunas antigubernamentales, otras hacían referencia a situaciones académicas, o a las disputas entre diversos grupos de la izquierda, por ejemplo.
} 
Los reclamos no sólo fueron contra el Gobierno de Charles De Gaulle sino sobre toda la estructura de partidos, incluso los opositores, como fue el caso de los Partidos socialista y comunista. Este último aspecto develó la pérdida de hegemonía en la izquierda tradicional frente a otras variantes más radicalizadas (trotskistas, maoístas, anarquistas, etc).

Las oscilaciones del gobierno, entre la búsqueda de una negociación y la aplicación de una feroz represión, incrementaron la incertidumbre. Finalmente, el 25 se abrieron las conversaciones con las organizaciones obreras que culminaron con los Acuerdos de Grenelle que fijaron un aumento del salario mínimo y otro para todos los trabajadores.

Sin embargo, las movilizaciones no terminaron, a pesar que el 30 de mayo el general Charles De Gaulle anunció la disolución de la Asamblea Nacional y que no dimitiría proclamando un lema "el caos o yo", sólo comenzaron a disolverse con el pago de los días caídos y el aislamiento de los estudiantes que continuaron padeciendo la represión de la CRS y el encarcelamiento de sus principales líderes.

Luego de tanta agitación a fines de junio, se llevaron a cabo elecciones, ordenada por el General De Gaulle, y en las cuales el gobierno reforzó su posición a través la Unión de Demócratas por la Republica que ganó por un 38 \%, en cambio los comunistas y socialistas tuvieron fuertes retrocesos.

Esta claro que De Gaulle aprovechó las contradicciones de la alianza obreroestudiantil, ofreciendo cumplir los objetivos más precisos y concretos de los primeros, para sacarle fuerza al movimiento, dejando de lado los más profundos, y menos precisos también, del Movimiento "22 de Marzo".

\section{Las ramificaciones del 68}

Pero el malestar no estaba sólo en Occidente, en Checoslovaquia se produjo la llamada Primavera de Praga en donde el presidente Alexander Dubcek tuvo la iniciativa de transformar al socialismo burocrático, proponiendo un sistema pluripartidario con respeto a la libertad de expresión, pero manteniéndose en el Bloque Oriental.

Ante las resistencias de algunos sectores a favor del status quo a nivel local y la desconfianza de Moscú, se reclamó dar marcha atrás con ellas, cuestión que causó la movilización y radicalización de la población que culminó con la intervención de las fuerzas del Pacto de Varsovia sobre Praga con lo que se dio por terminado esa iniciativa política.

Incluso, América Latina que no había sido inmune al movimiento de los sesenta por la Revolución Cubana, tuvo otros coletazos como las protestas universitarias en México que llevaron a la matanza de Tlatelolco en 1968 y el Cordobazo en Argentina al año siguiente fueron una muestra de ello.

\section{La respuesta a los sesenta:}

Como ya señalamos, los setenta concluyen hacia 1973 con una crisis estructural que afectó al mundo creado en la última posguerra, tanto en sus fundamentos materiales, el Estado de Bienestar, como en el rechazo a aquella agitación política que describimos. 
La necesidad de revertir esas causas permitió la aparición de una reacción, bajo la forma de la "Nueva Derecha", la cual según Alain Finkelkraut (1982) se compuso de una mezcla de la utopía que propuso un New Deal, al revés y la revancha de los años sesenta.

Este nuevo sustrato cultural en el que aun vivimos, llevó adelante la remoción de los cimientos materiales y político de la posguerra, sino que resignificó algunas consignas del 68 , sobre todo aquellas que giraron en torno al individualismo que eran funcionales al discurso neoliberal. Incluso la vinculación entre los sesenta y el estructuralismo expresada por alguna bibliografía fue denunciada por Castoriadis, quien no dudo en expresar que los manifestantes de entonces hubieran lanzado "carcajadas inextinguibles" si se les hubiese planteado esa cuestión. (Castoriadis 2006, 146) ${ }^{7}$

\section{Conclusiones}

Las banderas del 68, nos llegaron resignificadas a través de los cristales de las dos décadas siguientes fundamentalmente, donde fueron vaciadas de sus contenidos originales y refuncionalizadas para un proyecto que se encuentran en las antípodas de sus motivaciones.

Fue la reacción a los sesenta, lo que permaneció entre nosotros con todas las fórmulas de prefijos, pos, neo, entre otros, y que hoy nos habitan.

Tomemos como ejemplo la resignificación de la democracia que se encontró vaciada de sus contenidos más liberadores, más directa, sin intermediaciones como se reclamaba por aquellos días, y que en la actualidad se presenta como instrumentos del estatus quo de la sacralización del mercado.

Para terminar, lo hacemos con unas palabras de evaluación del mayo del 68 que Cornelius Castoriadis hizo a veinte años de aquél, y que suscribimos integralmente por su actualidad:

... están los que consideran - es mi caso-, que los márgenes de libertad que implica el régimen contemporáneo no son sino subproductos sedimentados desde hace varios siglos de movimientos de este tipo; que sin estos movimientos el régimen no solo no habría producido nunca esas libertades, sino que cada vez las habría recortado inexorablemente (como esta pasando); que, finalmente, la humanidad puede mejorar. Están también los que piensan -raramente se animan a decirlo, salvo evidentemente "desde la derecha", pero sus argumentos y sus razonamientos apuntan a eso- que vivimos en la forma por fin encontrada de la sociedad política libre y justa... Aquí la discusión solo puede detenerse, y cada uno hace sus elecciones o confirma las que ya hizo. (Castoriadis, 2009, p.152)

\section{Bibliografía consultada:}

\footnotetext{
${ }^{7}$ El estructuralismo no los apoyaba porque era la ideología dominante entre los profesores y contra ellos fue el movimiento que luego hayan tratado de reacomodarse ante los cambios fue distinto a decir que lo originaron.
} 
-Aron, Raymond. 1983. El Observador comprometido. Buenos Aires, Emecé.

-Cohn-Bendit, Daniel, Sartre, Jean-Paul y Marcuse, Hebert. 1982. La imaginación al poder. Barcelona, Argonauta.

-Cohn-Bendit, Daniel. 1987. La revolución y nosotros, que la quisimos tanto. Barcelona, Anagrama.

-Finkelkraut, Alain. 1982. La nueva derecha norteamericana. Barcelona, Anagrama.

-Hobsbawn, Eric. 1995. Historia del Siglo XX. 1914-1991. Barcelona, Crítica.

-Hobsbawn, Eric. 2009. Años interesantes. Una vida en el Siglo XX. Barcelona, Crítica.

-Jagger, Mike y Richards, Keith. 1968. "Street fighting man" (Luchador Callejero) en: The Rolling Stones, Single: Beggars Banquet, Londres, EP

-Jamenson, Fredric. 1997. Periodizar los 60. Córdoba, Alción

-Judt, Tony. 2009. Postguerra. Una historia de Europa desde 1945. Madrid, Taurus.

-Morin, Edgar, Lefort, Claude y Castoriadis, Cornelius. 2009. Mayo del 68: la brecha. Buenos Aires, Nueva Visión. 